\title{
De novo macrolide-glycolipid macrolactone hybrids: Synthesis, structure and antibiotic activity of carbohydrate-fused macrocycles
}

\author{
Richard T. Desmond ${ }^{1}$, Anniefer N. Magpusao ${ }^{1}$, Chris Lorenc ${ }^{1}$, Jeremy B. Alverson ${ }^{2}$, \\ Nigel Priestley ${ }^{2}$ and Mark W. Peczuh ${ }^{* 1}$
}

\author{
Full Research Paper \\ Address: \\ ${ }^{1}$ Department of Chemistry, University of Connecticut, $55 \mathrm{~N}$. Eagleville \\ Road, U3060, Storrs, CT 06269, USA, +1-860-486-1605 FAX: \\ +1-860-486-2981 and ${ }^{2}$ Department of Chemistry and Biochemistry, \\ University of Montana, Missoula, MT 59812, USA \\ Email: \\ Mark W. Peczuh* - mark.peczuh@uconn.edu \\ * Corresponding author \\ Keywords: \\ antibiotic; carbohydrate; exo-anomeric effect; macrolide; structure; \\ synthesis
}

\author{
Beilstein J. Org. Chem. 2014, 10, 2215-2221. \\ doi:10.3762/bjoc. 10.229 \\ Received: 20 June 2014 \\ Accepted: 29 August 2014 \\ Published: 17 September 2014 \\ Associate Editor: D. Spring \\ (C) 2014 Desmond et al; licensee Beilstein-Institut. \\ License and terms: see end of document.
}

\begin{abstract}
Natural product-like macrocycles were designed as potential antibacterial compounds. The macrocycles featured a D-glucose unit fused into a 12- or 13-member macrolactone. The rings are connected via the C6' and anomeric (C1') positions of the monosaccharide. The new macrocycles/macrolides were characterized by X-ray crystallography. Their structures showed that, in addition to the ester and alkene units, the dihedral angle about the glycosidic linkage (exo-anomeric effect) influenced the overall shape of the molecules. Glycosylation of an available hydroxy group on the macrocycle gave a hybrid macrolide with features common to erythromycin and sophorlipid macrolactone. Weak antibiotic activity (MICs $<100 \mu \mathrm{g} / \mathrm{mL}$ ) was observed for several of the compounds.
\end{abstract}

\section{Introduction}

In contemporary usage, "macrolide" describes any large ring lactone [1]. It was originally coined, however, with reference to a narrower set of compounds: antimicrobial natural products containing a macrolactone ring adorned with deoxygenated carbohydrate residues [2]. Erythromycin (1, Figure 1), for example, is an archetypal macrolide due to its molecular structure as well as its antibiotic activity; it is used clinically to treat

Gram positive bacterial infections. The mechanism of action of erythromycin is via inhibition of bacterial protein synthesis $[3,4]$. Sophorolipid lactone 2 [5], on the other hand, represents one example of glycolipid macrolactone natural products. These novel compounds have many potential applications (e.g., food, cosmetics) based on their physical properties; some glycolipid lactones have also been shown to be cytotoxins [6] and $\mathbf{2}$ also 
has antibacterial activity [7,8]. Over time, antibiotic use has created a selection pressure that has led to bacterial resistance and a subsequent need for continuous development of new antibiotics. Despite cumbersome syntheses, erythromycin analogs continue to be used as front line antibiotics while the clinical potential of glycolipid macrolactones has yet to be evaluated. The novel structures and biological activities of these natural products provide inspiration for the design and synthesis of new, related compounds that bear a resemblance to them.

We [9-12], among others [13-19], have investigated compounds that blend features of macrolides and glycolipid lactones. These natural product-like compounds fuse the carbohydrate ring to the macrocycle rather than connecting them through a glycosidic linkage. Compounds $\mathbf{3}$ and $\mathbf{4}$ in Figure 1 illustrate one approach that has been reported. Here oxygens at the $\mathrm{C} 6$ and $\mathrm{C} 4$ positions of a pyranose provide two linkage points between the macrocycle and the carbohydrate. Atoms of the carbohydrate are integral to the structure of the macrocycle to form a 13-membered ring in $\mathbf{3}$ and an 18-membered ring in $\mathbf{4}$. In addition to the number of atoms in the ring, the presence of rigidifying planar units and stereocenters collectively govern the shape of a given macrocycle. In fact, we observed that the absolute configuration of $\mathrm{C} 4$ of the pyranose ring strongly influenced the shape and reactivity of macrocycle $\mathbf{3}$ [9]. In $\mathbf{3}$, the oxygens at $\mathrm{C} 4$ and $\mathrm{C} 6$ are both part of ester linkages; in $\mathbf{4}$ they are a carbamate and ether, respectively. Modest antifungal activity against $C$. neoformans and A. fumigatis were also noted for 4 [13]. Here we report on two new natural product-like 12-membered ring macrolides 5 and $\mathbf{6}$ (Scheme 1) where the pyranose is fused to the macrocycle through the C1' (glycosidic) and C6' oxygens. The new macrolides bear a resemblance to sophorolipid lactone $\mathbf{2}$ and to polyketide macrocycles that contain a tetrahydropyran moiety [20-22]. We report on the synthesis, X-ray crystal structures and antibiotic activities of the new compounds.

\section{Results and Discussion}

The syntheses of $\mathbf{5}$ and $\mathbf{6}$ (Scheme 1) generally followed a ring closing metathesis (RCM) strategy that had been established previously [9]. C4,C6-O-Benzylidene-protected allyl glucoside 7 , as a mixture of $\alpha$ - and $\beta$-anomers, was the starting material for the synthesis. In the first step, the C2 and C3 hydroxy groups were converted to methyl ethers via alkylation with iodomethane in the presence of sodium hydride to give compounds $8 \mathbf{a}$ and $8 \mathbf{b}(3: 1,66 \%$ combined yield). At this point the $\alpha$ - and $\beta$-anomers could be separated by column chromatography. Each anomer was then carried through the remainder of the synthesis separately. Transacetalization of the $\mathrm{C} 4, \mathrm{C} 6-\mathrm{O}-$ benzylidene protecting group in methanol provided diols $9 \mathbf{a}$ and $\mathbf{9 b}$, respectively in nearly quantitative yields. Chemoselective, DCC-mediated acylation of the primary alcohol group of $9 \mathbf{a}$ and 9b at $0{ }^{\circ} \mathrm{C}$ with pentenoic acid gave $10 \mathrm{a}(58 \%)$ and $\mathbf{1 0 b}(56 \%)$.

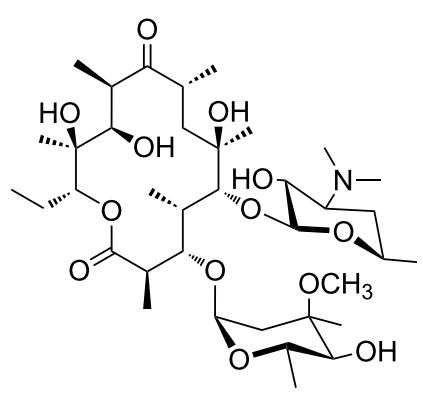

erythromycin 1

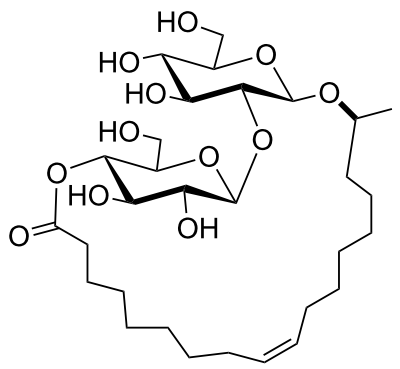

sophorolipid lactone 2<smiles>COC1OC(COC(=O)CC[C@@H]2O[C@H]2Cc2ccccc2)[C@H](OCc2ccccc2)[C@H](Cc2ccccc2)[C@@H]1O</smiles>

D-galactose-[13]-macrodiolide 3

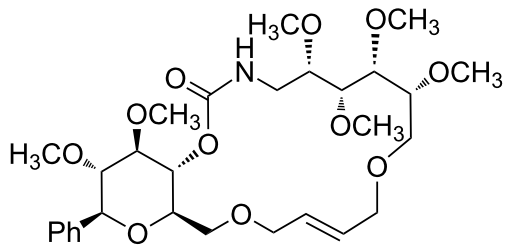

D-glucose-[18]-macrocycle 4

Figure 1: Erythromycin (1), the archetypal macrolide; sophorlipid lactone 2, a glycolipid macrolactone; $\beta$-D-galactose fused-[13]-macrodiolide 3 and $\beta$-D-glucose-fused [18]-macrocycle 4. 


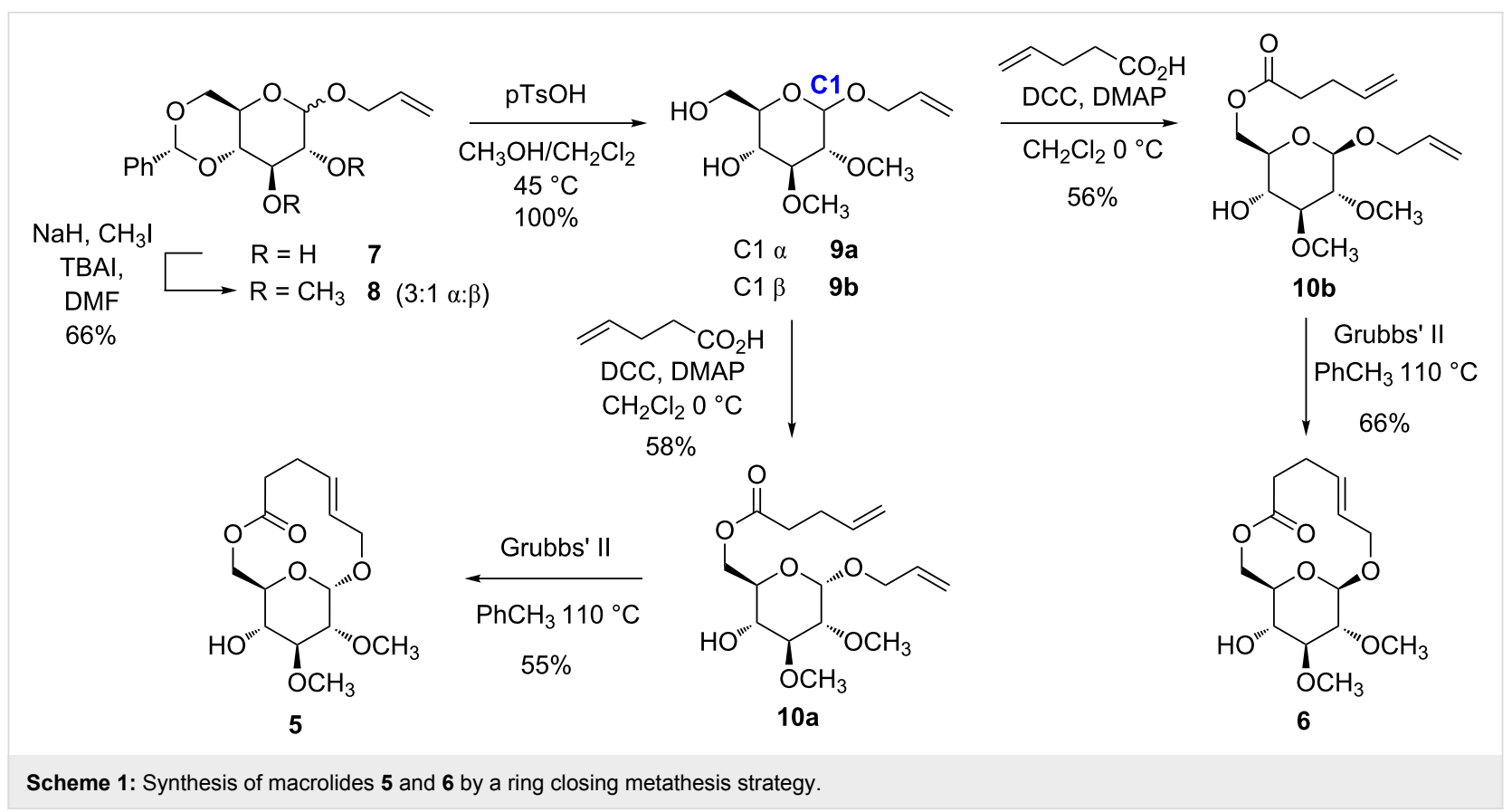

Compounds 10a and 10b were poised for RCM by virtue of the two alkenes present in them. RCM of each one, using the second generation Grubbs catalyst, provided $E$-configured macrolides 5 and $\mathbf{6}$ in 55 and $66 \%$ yield. Both compounds were isolated as crystalline solids after purification by column chromatography. Recrystallization of each, from a mixture of hexanes and ethyl acetate, provided crystals of sufficient quality to determine their structures by X-ray crystallography.

We are broadly interested in understanding how molecular/conformational features such as planar multi-atom units, stereogenic centers and stereoelectronic effects combine to dictate the "topology" or overall fold of a macrocycle. The structure of $\beta$-D-galactose-[13]-macrodiolide 3 [9], derived from X-ray data, originated this line of investigation. It showed that both esters and the epoxide unit are each composed of four coplanar atoms that significantly reduce the number of freely rotatable bonds in the molecule $[9,10,12,23-25]$ and rigidify its structure. The consequence is that the esters, alkene and epoxide units are not coplanar, but are set at angles to each other (Figure 2 ). The result is a twist in the backbone of the macrocycle whose chirality is dictated by the absolute configuration of the $\mathrm{C} 4$ stereogenic center. The topology is a defining feature of this family of [13]-macrodiolides. By virtue of the planar chirality, [13]-macrodiolides such as $\mathbf{3}$ have an axis of chirality associated with them. We were therefore interested to see how the ester and allyl units of $\mathbf{5}$ and $\mathbf{6}$ would affect their overall structures. We were equally interested in the role that the glycosidic linkage has in governing each macrocycle's shape.
The structures of $\mathbf{5}$ and $\mathbf{6}$, derived from X-ray crystallographic data, share several characteristics (Figure 3) [26]. The main structural features for these compounds are the D-glucose ring and the macrocyclic ring. The $\alpha$-D-glucosyl unit in $\mathbf{5}$ and the $\beta$-D-glucosyl unit in 6 both adopt the common ${ }^{4} \mathrm{C}_{1}$ chair conformation of D-pyranosides. Further, the hydroxymethyl group of the D-glucosyl unit (defined as the torsional angle about the C5'-C6' bond) is in the gt conformation for each structure [27]. An intramolecular hydrogen bond between the C4' hydroxy group and the C3' oxygen is also apparent in $\mathbf{5}$ whereas in $\mathbf{6}$ the same hydroxy group is hydrogen-bonded to a bound water molecule. Observations made regarding the macrolactone moiety of 5 and $\mathbf{6}$ references the atom numbering shown in Table 1. Dihedral angles close to $180^{\circ}$ for the $\mathrm{C} 4-\mathrm{C} 5$ alkene and the $\mathrm{C} 8$ ester indicated that these groups are nearly planar; these units are akin to those that rigidified the [13]-macrodiolide ring in 3 (Figure 2). An additional coplanar, four-atom sequence spanned from $\mathrm{C} 10-\mathrm{C} 11-\mathrm{O} 12-\mathrm{C} 1$; it was unanticipated that this unit, which includes the glucosyl ring oxygen, would be planar. Atom $\mathrm{C} 10$ of the macrocycle (C6' using D-glucose numbering) is consequently common to two of the three planar units in the macrocycle. The $\mathrm{C} 9-\mathrm{C} 10-\mathrm{C} 11$ bond angle of $108-110^{\circ}$ indicates that $\mathrm{C} 10$ can accommodate both planes and does not distort from the normal $\mathrm{sp}^{3}$ hybridization. A schematic rendition of the macrocycle that depicts the planar units and their orientations is also included in Table 1 .

The three rigidifying units create a roughly triangular shape to the backbone of the macrocycle (e.g., 6 in Figure 3d) and the 
a<smiles>C1C[C@H]2CC[C@@H](CO2)O1</smiles>

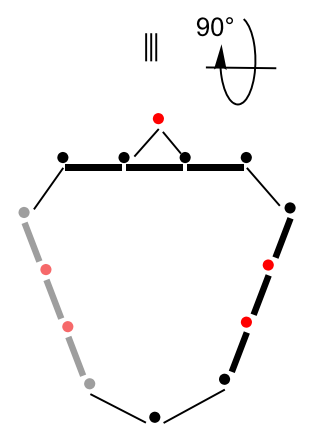

b

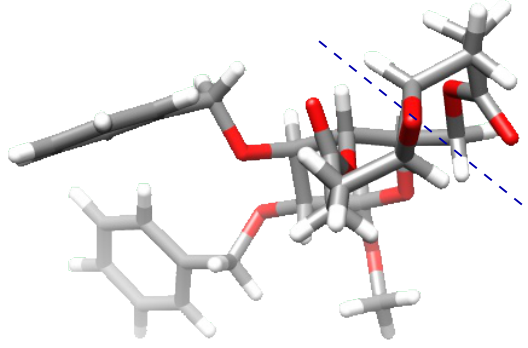

C

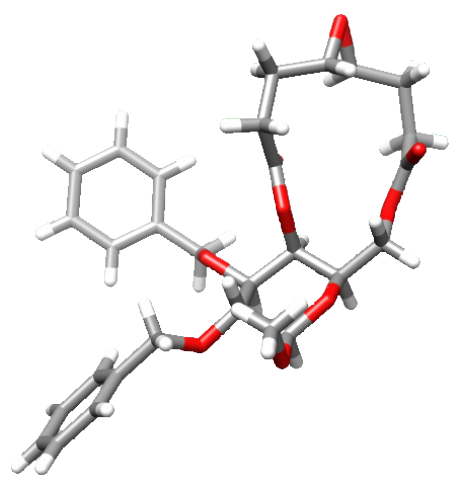

Figure 2: Structure of macrolide 3; a) schematic representation of 3 emphasizing four-atom planar units of the [13]-macrodiolide motif; b) and c) the structure of 3 from X-ray data that corresponds to the schematic representation. An axis of chirality associated with the topology of the macrocycle is indicated with a dashed line in b).

a

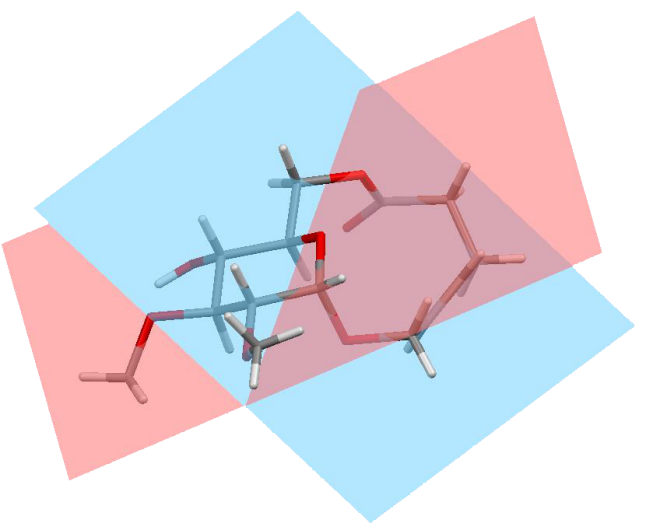

b

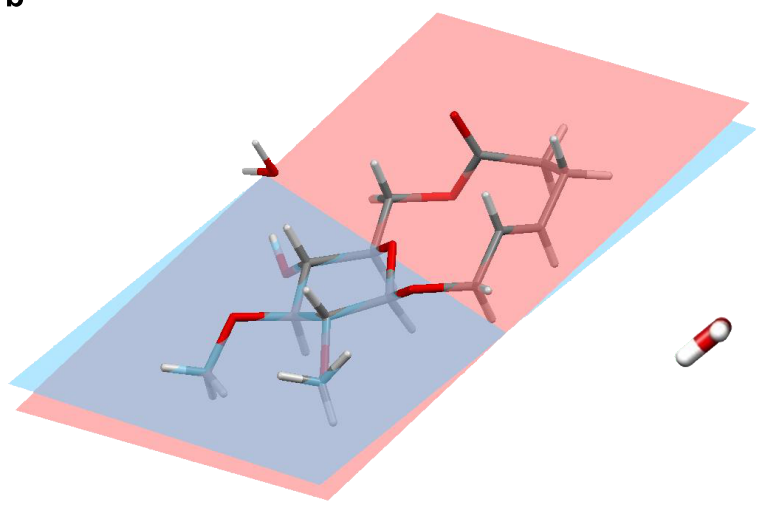

c

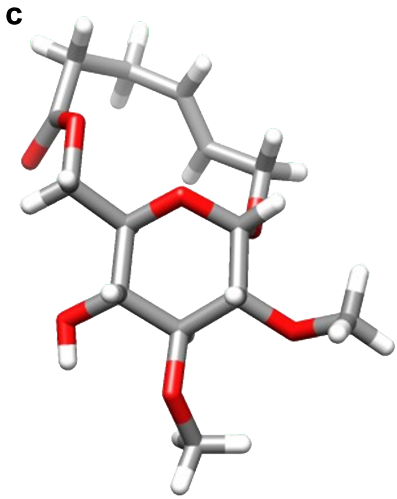

d

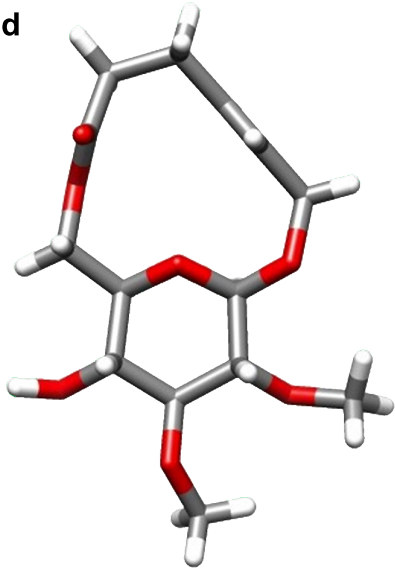

e

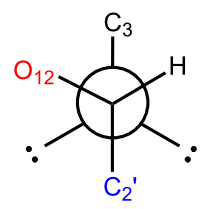

f

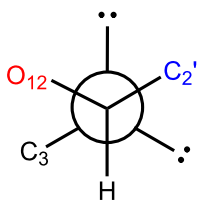

Figure 3: Structures of $\mathbf{5}$ and $\mathbf{6}$ from X-ray crystallographic data; a) and b) side views of $\mathbf{5}(\mathrm{a})$ and $\mathbf{6}$ (b) with mean plane of macrocycle in blue and D-glucose in red; c) and d) views of $\mathbf{5}$ and $\mathbf{6}$ from an angle perpendicular to the D-glucose plane; e) and f) Newman projections, sighting down the glycosidic bond, of 5 and 6 . 
Table 1: Selected bond angles for 5 and 6 from X-ray crystallographic data.

Planar units:
C3-C4-C5-C6 (alkene)
C7-C8-C9-C10 (ester)
C10-C11-O12-C1
Dihedrals:
C5-C6-C7-C8
C11-O12-C1-O2
O12-C1-O2-C3 (exo-anomeric)
D-glucose C5'-C6'(C10) rotamer
Angles:
C9-C10-C11

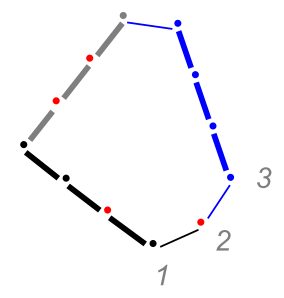

$5(\alpha)$

$6(\beta)$

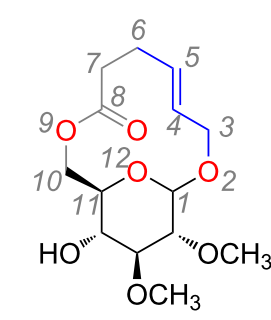

$5 \mathrm{C} 1-\mathrm{O} 2 \alpha$

$6 \mathrm{C} 1-\mathrm{O} 2 \beta$

$\begin{array}{ll}176.81 & 179.07 \\ 170.19 & 170.66 \\ 179.24 & 168.54 \\ & \\ -58.78 & -63.23 \\ 60.65 & -175.85 \\ 66.11 & 75.33 \\ 65.46 \text { (gt) } & -66.90 \text { (gt) } \\ & \\ 109.92 & 107.97\end{array}$

relative orientation of these units creates a macrocyclic plane. When comparing $\mathbf{5}$ and $\mathbf{6}$, the relationship between the mean planes defined by the glucose and the macrocycle is clearly different. Specifically, the two planes are set at an angle to each other in $\mathbf{5}$ whereas in $\mathbf{6}$ the two planes are essentially coincident. The relationship of the two planes tends to warp macrocycle 5 but not $\mathbf{6}$, which is essentially planar. It is the configuration of the anomeric carbon that governs the difference in the structures. First and foremost, the axial (5) versus equatorial (6) positioning of the anomeric oxygen, and subsequently the aglycone, dictates the orientation of the D-glucose- and macrocyclic planes. Relatedly the exo-anomeric effect [28,29] plays a role in determining the orientation of the backbone of the macrocycle relative to the pyranose. The exo-anomeric effect is a stereoelectronic effect concerned with the donation of electron density from a lone pair on the aglycone oxygen $(\mathrm{O} 2)$ into the $\sigma^{*}$ antibonding orbital of the $\mathrm{O} 12-\mathrm{C} 1$ bond. Figure $3 \mathrm{e}$ and Figure $3 \mathrm{f}$ show the Newman projections for the glycosidic bond showing the antiperiplanar relationship between the ring oxygen (O12) and the lone pair of the aglycone oxygen (O2). This configuration is stabilizing because it enables delocalization of electron density and it must be balanced with the need to accommodate the steric bulk of the aglycone - in this case the macrocyclic ring. In total it is the balancing of a number of small factors such as rigidification by multi-atom planar units, absolute configuration of stereogenic centers and stereoelectronic effects that dictate the observed structures.

Minimum inhibitory concentrations (MICs) against a variety of organisms were determined for macrocycles $\mathbf{5}$ and $\mathbf{6}$ to assess their antibiotic activity (Table 2). Notably, the MIC for $\alpha$-macrolide 5 was $<100 \mu \mathrm{g} / \mathrm{mL}$ against $B$. subtilis and $B$. anthracis. Based on this initial activity, we prepared a series of analogs of 5 by derivatizing the C4' hydroxy group. This was possible by virtue of the original $\mathrm{C} 4, \mathrm{C} 6$ diol 9a; chemoselective acylation of the primary alcohol (C6') unit left the C4' alcohol available for additional reactions. Analogs were prepared under precedented conditions to give 11-16 in good yields. Analog 17, which contains a saturated macrocyle, was also prepared. Among them, only analogs 11 and 16 had MICs that were similar to $\mathbf{5}$ while the other analogs showed no antibiotic activity. Glycosylated analog 16 combines the features of erythromycin and sophorlipid macrolactone. That is, a glycosylated macrocycle feature that defines the macrolides is added to the cyclic glycolipid macrolactone feature of the sophorlipids. De novo macrolide $\mathbf{1 6}$ was active against $B$. anthracis, with a MIC of $115 \mu \mathrm{g} / \mathrm{mL}$. A 13 -membered ring analog of 5 was prepared by acylating 10c with 5-hexenoyl chloride followed by RCM to give 19. This compound also had some activity against $S$. pyogenes and $B$. subtilis. Although the mechanism of action of the family of antibiotic macrocycles in Table 2 is not defined, the compounds were designed as protein synthesis inhibitors [3,30]. Compounds $\mathbf{1 1}$ and $\mathbf{1 8}$ have the lowest MIC values reported here. They are the $\alpha$ - and $\beta$-12membered ring macrocycles with a $\mathrm{C} 4$ '-O-tert-butyldimethylsilyl group. MICs as low as $52 \mu \mathrm{g} / \mathrm{mL}$ against $S$. aureus, E. faecalis, and B. subtillis were observed. The small data set and low activity of the compounds prevent a QSAR analysis but the influence of a $\log \mathrm{P}$ effect seems most likely [31-33]. 
Table 2: MIC ( $\mu \mathrm{g} / \mathrm{mL})$ values for compounds 5, 6 and 11-19.<smiles>[R6]C1O[C@H]1COC(=O)CC/C=C/CO[C@H]1O[C@H](OC)[C@@H](OC)[C@H](OC)[C@@H]1O</smiles>

$5 \quad \mathrm{R}=\mathrm{H}$

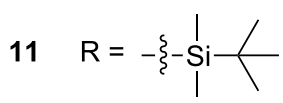

$12 \mathrm{R}=3 \widehat{T}_{\mathrm{Ph}}$<smiles>[R6]C1O[C@H]1COC(=O)CC/C=C/CO[C@H]1O[C@H](OC)[C@@H](OC)[C@H](O)[C@H]1OC</smiles>

$13 \mathrm{R}=$<smiles>[Te]=C1CCCCO1</smiles>

14<smiles>[R]=[Te][C]1CCCCO1</smiles>

$6 \mathrm{R}=\mathrm{H}$

18<smiles>[R][Y][Si](C)(C)[Si](C)(C)C(C)(C)C</smiles>

15

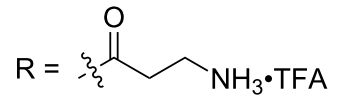

16

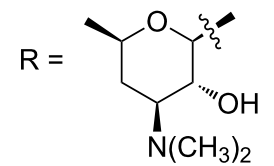

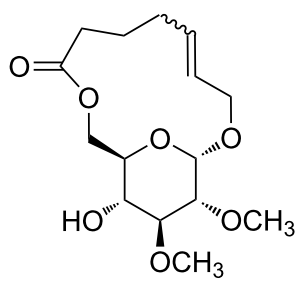<smiles>CO[C@H]1O[C@H](COC(=O)CCCCCO[C@H]2O[C@H]2OC)[C@@H](O)[C@@H](O)[C@@H]1O</smiles>

17

19

\begin{tabular}{lccccccccccc}
\hline & $\mathbf{5}$ & $\mathbf{1 1}$ & $\mathbf{1 2}$ & $\mathbf{1 3}$ & $\mathbf{1 4}$ & $\mathbf{1 5}$ & $\mathbf{1 6}$ & $\mathbf{1 7}$ & $\mathbf{6}$ & $\mathbf{1 8}$ & $\mathbf{1 9}$ \\
\hline S. aureus & 151 & $\mathbf{5 2}$ & $>392$ & $>302$ & $>302$ & $>244$ & $>460$ & $>304$ & $>302$ & $\mathbf{5 2}$ & 158 \\
E. faecalis & 151 & $>416$ & $>392$ & $>302$ & $>302$ & $>244$ & $>460$ & $>304$ & 302 & $\mathbf{5 2}$ & 158 \\
S. pyogenes & 151 & $\mathbf{1 0 4}$ & $>392$ & $>302$ & $>302$ & - & - & - & 151 & $>208$ & $\mathbf{8 0}$ \\
B. subtilis & $\mathbf{7 6}$ & $\mathbf{5 2}$ & $>392$ & $>302$ & $>302$ & $>244$ & 460 & 304 & 302 & $\mathbf{5 2}$ & $\mathbf{8 0}$ \\
B. anthracis & $\mathbf{7 6}$ & 208 & $>392$ & $>302$ & $>302$ & $>244$ & $\mathbf{1 1 5}$ & $>304$ & $>302$ & $>208$ & 158 \\
K. pneumoniae & $>600$ & - & $>392$ & $>302$ & $>302$ & - & - & - & - & $>208$ & - \\
P. aeruginosa & $>600$ & $>416$ & $>392$ & $>302$ & $>302$ & $>244$ & $>460$ & $>304$ & $>302$ & $>208$ & $>316$ \\
E. coli & $>600$ & - & $>392$ & $>302$ & $>302$ & - & - & - & - & $>208$ & ND \\
C. glabrata & $>600$ & $>416$ & $>392$ & $>302$ & $>302$ & - & - & - & $>302$ & $>208$ & $>316$ \\
C. albicans & 151 & $>416$ & $>392$ & $>302$ & $>302$ & $>244$ & $>460$ & $>304$ & $>302$ & $>208$ & $>316$
\end{tabular}

\section{Conclusion}

We have described the synthesis and characterization of de novo macrolide $\mathbf{1 6}$ as a member of a family of related macrocyles that fuse a pyranose monosaccharide to the macrocyclic ring. The new compounds showed modest antibacterial activity against Gram positive organisms. The main conclusion of the work, however, relates the role of the exo-anomeric effect on the low-energy conformation of macrocycles linked through an anomeric center. This weak stereoelectronic effect should be listed with other factors such as ring size, multi-atom planar units, and stereogenic centers as determinants of macrocylic topology. These features will likely play a role in the future design of new macrocycles with specific structures and functions. It also provides a useful basis for developing SAR of macrocyclic natural products.

Crystallographic data for $\mathbf{5}$ and $\mathbf{6}$ are in the Cambridge Crystallographic Data Centre (CCDC), No. 1006597 and 1006598. Copies of this information may be obtained free of charge from CCDC, 12 Union Road, Cambridge CB2 1EZ, UK (Fax: +441223-336033; web: http://www.ccdc.cam.ac.uk; email: deposit@ccdc.cam.ac.uk).

\section{Supporting Information}

\section{Supporting Information File 1}

Characterization data including ${ }^{1} \mathrm{H}$ and ${ }^{13} \mathrm{C}$ NMR spectra of all new compounds and ORTEP figures for $\mathbf{5}$ and $\mathbf{6}$.

[http://www.beilstein-journals.org/bjoc/content/ supplementary/1860-5397-10-229-S1.pdf]

\section{Supporting Information File 2}

Experimental procedures and characterization of all new compounds.

[http://www.beilstein-journals.org/bjoc/content/ supplementary/1860-5397-10-229-S2.pdf]

\section{Acknowledgements}

The NSF supported this work through a grant to MWP (CHE0957626). 400MHz/100MHz NMR spectra were collected on an instrument that was upgraded by an NSF-CRIF grant (CHE0947019). The Chemistry Instrumentation Center at Yale University is acknowledged for collection of X-ray data on $\mathbf{5}$ and 6. 


\section{References}

1. Nicolaou, K. C. Tetrahedron 1977, 33, 683-710. doi:10.1016/0040-4020(77)80180-4

2. Woodward, R. B. Angew. Chem. 1957, 69, 50-58. doi:10.1002/ange.19570690109

3. Yonath, A. Annu. Rev. Biochem. 2005, 74, 649-679 doi:10.1146/annurev.biochem.74.082803.133130

4. Dunkle, J. A.; Xiong, L.; Mankin, A. S.; Cate, J. H. D. Proc. Natl. Acad. Sci. U. S. A. 2010, 107, 17152-17157. doi:10.1073/pnas.1007988107

5. Fürstner, A.; Radkowski, K.; Grabowski, J.; Wirtz, C.; Mynott, R. J. Org. Chem. 2000, 65, 8758-8762. doi:10.1021/jo0012952

6. Chen, J.; Song, X.; Zhang, H.; Qu, Y.-b.; Miao, J.-y. Appl. Microbiol. Biotechnol. 2006, 72, 52-59. doi:10.1007/s00253-005-0243-z

7. Gupta, R.; Kumar, U. S.; Prabhune, A. Res. J. Biotechnol. 2012, 7, 40-45.

8. Kim, K.; Yoo, D.; Kim, Y.; Lee, B.; Shin, D.; Kim, E.-K. J. Microbiol. Biotechnol. 2002, 12, 235-241.

9. Fyvie, W. S.; Peczuh, M. W. J. Org. Chem. 2008, 73, 3626-3629. doi:10.1021/jo800027y

10. Fyvie, W. S.; Peczuh, M. W. Chem. Commun. 2008, 4028-4030. doi:10.1039/b807562j

11. Ma, J.; Peczuh, M. W. J. Org. Chem. 2013, 78, 7414-7422. doi:10.1021/jo400383g

12. Ma, J.; Vannam, R.; Terwilliger, D.; Peczuh, M. W. Tetrahedron Lett. 2014, 55, 4255-4259. doi:10.1016/j.tetlet.2014.05.081

13. Ruttens, B.; Blom, P.; Van Hoof, S.; Hubrecht, I.; Van der Eycken, J. J. Org. Chem. 2007, 72, 5514-5522. doi:10.1021/jo061929q

14. Blom, P.; Ruttens, B.; Van Hoof, S.; Hubrecht, I.; Van der Eycken, J. J. Org. Chem. 2005, 70, 10109-10112. doi:10.1021/jo051021k

15. Horvat, Š.; Roščić, M.; Varga-Defterdarović, L.; Horvat, J. J. Chem. Soc., Perkin Trans. 1 1998, 909-914. doi:10.1039/A707509J

16. Potopnyk, M. A.; Cmoch, P.; Jarosz, S. Org. Lett. 2012, 14 , 4258-4261. doi:10.1021/ol301993d

17. Ajay, A.; Sharma, S.; Gupt, M. P.; Bajpai, V.; Kumar, B.; Kaushik, M. P.; Konwar, R.; Ampapathi, R. S.; Tripathi, R. P. Org. Lett. 2012, 14, 4306-4309. doi:10.1021/ol3022275

18. Allam, A.; Dupont, L.; Behr, J.-B.; Plantier-Royon, R. Eur. J. Org. Chem. 2012, 817-823. doi:10.1002/ejoc.201101406

19. Billing, J. F.; Nilsson, U. J. J. Org. Chem. 2005, 70, 4847-4850. doi:10.1021/jo050585।

20. Nasir, N. M.; Ermanis, K.; Clarke, P. A. Org. Biomol. Chem. 2014, 12, 3323-3335. doi:10.1039/c4ob00423j

21. Crane, E. A.; Scheidt, K. A. Angew. Chem., Int. Ed. 2010, 49, 8316-8326. doi:10.1002/anie.201002809

22. Larrosa, I.; Romea, P.; Urpi, F. Tetrahedron 2008, 64, 2683-2723. doi:10.1016/j.tet.2007.11.092

23. Schreiber, S. L. Science 2000, 287, 1964-1969. doi:10.1126/science.287.5460.1964

24. Lee, D.; Sello, J. K.; Schreiber, S. L. J. Am. Chem. Soc. 1999, 121, 10648-10649. doi:10.1021/ja992658m

25. Kim, Y.-k.; Arai, M. A.; Arai, T.; Lamenzo, J. O.; Dean, E. F., III; Patterson, N.; Clemons, P. A.; Schreiber, S. L. J. Am. Chem. Soc. 2004, 126, 14740-14745. doi:10.1021/ja048170p

26. Absolute configuration has not been established by anomalous-dispersion effects in diffraction measurements on the crystal. Rather, the enantiomer has been assigned by reference to several chiral centers, present in the starting material (D-glucose), that remain unchanged throughout the synthetic procedure.
27. Stenutz, R.; Carmichael, I.; Widmalm, G.; Serianni, A. S. J. Org. Chem. 2002, 67, 949-958. doi:10.1021/j0010985i

28. Tvaroŝka, I.; Bleha, T. Adv. Carbohydr. Chem. Biochem. 1989, 47, 45-123. doi:10.1016/S0065-2318(08)60412-6

29. Lemieux, R. U.; Koto, S.; Voisin, D. The Exo-Anomeric Effect. In Anomeric Effect: Origin and Consequences; Szarek, W. A.; Horton, D., Eds.; ACS Symposium Series 87; American Chemical Society: Washington, D.C., 1979; pp 17-29. doi:10.1021/bk-1979-0087.ch002

30. Maffioli, S. I.; Fabbretti, A.; Brandi, L.; Savelsbergh, A.; Monciardini, P.; Abbondi, M.; Rossi, T.; Donadio, S.; Gualerzi, C. O. ACS Chem. Biol. 2013, 8, 1939-1946. doi:10.1021/cb4004095

31. McFarland, J. W.; Berger, C. M.; Froshauer, S. A.; Hayashi, S. F.; Hecker, S. J.; Jaynes, B. H.; Jefson, M. R.; Kamicker, B. J.; Lipinski, C. A.; Lundy, K. M.; Reese, C. P.; Vu, C. B. J. Med. Chem. 1997, 40, 1340-1346. doi:10.1021/jm960436i

32. Puratchikody, A.; Nagalakshmi, G.; Doble, M. Chem. Pharm. Bull. 2008, 56, 273-281. doi:10.1248/cpb.56.273

33. Li, F.; Mulyana, Y.; Feterl, M.; Warner, J. M.; Collins, J. G.; Keene, F. R. Dalton Trans. 2011, 40, 5032-5038. doi:10.1039/c1dt10250h

\section{License and Terms}

This is an Open Access article under the terms of the Creative Commons Attribution License (http://creativecommons.org/licenses/by/2.0), which permits unrestricted use, distribution, and reproduction in any medium, provided the original work is properly cited.

The license is subject to the Beilstein Journal of Organic Chemistry terms and conditions: (http://www.beilstein-journals.org/bjoc)

The definitive version of this article is the electronic one which can be found at: doi:10.3762/bjoc. 10.229 